\title{
Numerical prediction and experimental validation of sound transmission loss for different acoustic materials
}

\author{
Kirti S *, Mahavir S, Yudhister K Y
}

\footnotetext{
A \& V Metrology, PMM Division, CSIR-National Physical Laboratory, New Delhi -110012, India

* Corresponding Author: soniks@mail.nplindia.org
}

Received: 07-02-2018

Revised: 01-05-2018

Accepted: 07-05-2018

\begin{abstract}
This paper examines the sound transmission loss (STL) through multilayer panel materials commonly used in the building industry. The acoustic characteristics of different materials and multilayer panels are studied. Experimental data for the noise reduction coefficient in the frequency range 100 to $4000 \mathrm{~Hz}$ have been obtained using the two room's method. Mass theory is also used to predict the acoustic performance of these systems and to improve their acoustic performance with noise treatment.
\end{abstract}

Key words: Acoustic sample, Airborne Sound Insulation, Sound Transmission Loss, Mass theory.

\section{Introduction}

Increase in population, transportation, modern urbanization has applied pressure on all available resources. One of the severe problems of our urbanized society is related with unwanted and potentially unsafe noise. For the healthy and pleasant living and working environment, the development of effective ways and materials are required to minimize the noise pollution. It is essential to know the sound transmission loss of walls and floors so as to be able to compare different constructions, to determine acoustic privacy between flats or noise levels from outside sources.

Transmission loss (TL) is a performance of sound insulation measured in reverberation chambers and Sound Transmission Class (STC) is an integer rating of how well a building partition attenuates airborne sound.

Several studies have been focused on the development and analysis of sound absorbing devices made of a variety of porous materials, for example, fibrous, foams and granular materials etc. Moore and Lyon (1991); Lin et al., (2007); Wang et al., (2010) and Jung et al., (2015) reported the Sound Transmission Loss Characteristics of various acoustics materials. Building acoustics is the complex science of controlling noise in buildings. This contains the minimization of noise transmission from one space to another and the control of the characteristics of sound within spaces themselves. This study presents a comparison of experimental measurements of the sound transmission of walls, floor, ceilings etc. with the theoretical models.

\section{Methodology of testing and sample details}

\subsection{Measurement facilities and procedures}

The acoustical measurements were made in the suite of reverberation chambers in the acoustical block of the Acoustics and Vibration Metrology Section of CSIR-National Physical Laboratory, New Delhi. Wall panel samples are mounted in a removable test frame between two chambers, without rigid contact to either reverberation chambers. The panel test opening measures $0.93 \mathrm{~m} \times 0.63 \mathrm{~m}$. Both rooms are irregular in shape with no parallel surfaces and are equipped with stationary diffusers. The volume of the source room is $257 \mathrm{~m}^{3}$. The volume of the 
adjacent receiving room is $271 \mathrm{~m}^{3}$. Both reverberation chambers are supported on pillar with suitable vibration isolators. Test signals are supplied to each room by duo-decahedral loudspeakers system with independent pseudorandom noise sources. To measure transmission loss, white noise is fed to loudspeaker system in the source room. Pink noise is used to measure decays in the receiving room. The testing of acoustical materials (i.e., samples) was conducted in accordance with the requirement of ISO 10140-1:2016 sound pressure level and reverberation time measurements are made for 1/3-octave band with center frequencies from $100 \mathrm{~Hz}$ to 4000 $\mathrm{Hz}$. The data are then used to calculate sound transmission loss for each frequency band as per specified standards. A STC rating was obtained for each panel in accordance with ISO 101401:2016 and ASTM Standard Classification E413 (ASTM E413-87).

The sound transmission loss has been calculated as:

$S T L=L_{1}-L_{2}+10 \log _{10}\left(\frac{S}{A}\right)$

And the time constant governing the growth of the acoustic energy in the room is given by

$\tau_{E}=\frac{4 V}{A C}$

The reverberation time $\mathrm{T}$, defined as the time required for the level of the sound to drop by 60 $\mathrm{dB}$, is:

$\mathrm{T}=13.8 \tau_{E}=\frac{55.2 \mathrm{~V}}{A c}$

With Speed of sound in air c $=343 \mathrm{~m} / \mathrm{s}\left(20^{\circ} \mathrm{C}\right)$ this becomes

$A=\frac{0.612 \mathrm{~V}}{T}$ (Lawrence et al., 1982)

Where, L1: average sound pressure level in source room $(\mathrm{dB})$

L2: average sound pressure level in receiving room $(\mathrm{dB})$

$S:$ area of the test partition (in square meter)

A : total absorption area of receiving room (in square meter)

$\mathrm{V}$ : volume of receiving room (in cubic meter)

$\mathrm{T}:$ reverberation time $(\mathrm{sec})$

The evaluated uncertainty in measurement is $\pm 1.0 \mathrm{~dB}$ which is at a coverage factor $\mathrm{k}=2$ and which corresponds to a coverage probability of approximately $95 \%$ for normal distribution.

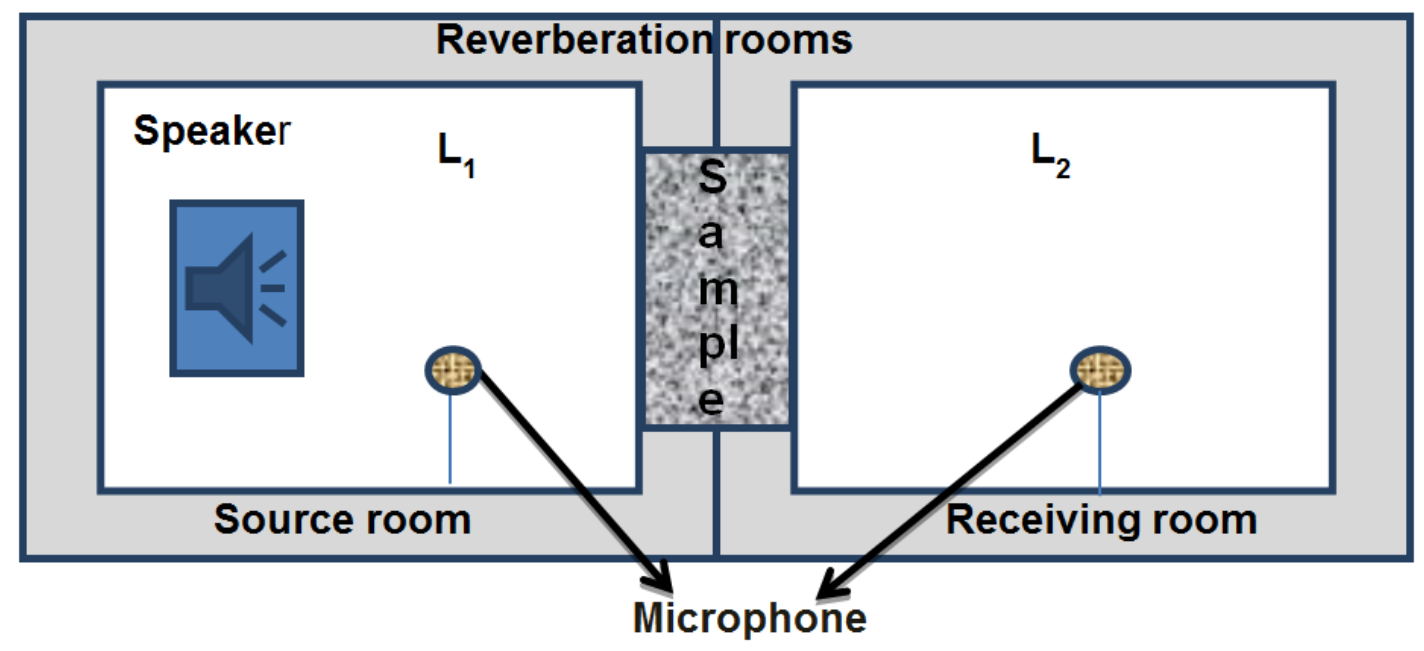

Fig. 1. Measurement of Sound Transmission Loss, STL, in the Laboratory 


\subsection{Theory for prediction}

In the present study, Mass theory has been used to predict the measured sound transmission loss. Mass Law provides a good working rule to predict the airborne sound insulation of a partition up to the region of the Critical Frequency and the Coincidence Effect

According to mass law, a doubling in Mass or Frequency results in a $6 \mathrm{~dB}$ increase in the sound insulation of a single leaf partition over a defined frequency range.

$T L=20 \log _{10}(\mathrm{fm})$

Where,

$\mathrm{f}=$ frequency of the sound

$\mathrm{m}=$ mass of the partition

To predict the performance of a material using the mass law the parameters Density of the material, Thickness of the material, Young's modulus, Damping coefficient etc. are required.

Table 1. Samples Details.

\begin{tabular}{|l|l|l|l|}
\hline Sample & $\begin{array}{l}\text { Name of } \\
\text { Manufacturer }\end{array}$ & Description of Items & Sound Transmission Class \\
\hline Sample 1. & $\begin{array}{l}\text { M/s. Shivathene } \\
\text { Linopack, Parwanoo - } \\
\text { HP }\end{array}$ & $\begin{array}{l}\text { 2 mm thick layer with PU } \\
\text { based 2 component sound } \\
\text { insulating paint (Shivabond } \\
\text { 603) coated on 2mm thick } \\
\text { MS Panel }\end{array}$ & $\begin{array}{l}\text { 4 mm thick Aluminium } \\
\text { Composite Panel }\end{array}$ \\
\hline Sample 2. & $\begin{array}{l}\text { M/S. Alstrong } \\
\text { Enterprises India } \\
\text { Private Limited, New } \\
\text { Delhi }\end{array}$ & $\begin{array}{l}\text { M/s. Fusion Building } \\
\text { Materials Private } \\
\text { Limited, Hyderabad }\end{array}$ & $\begin{array}{l}150 \text { mm thick AAC Block of } \\
\text { density 550-650 Kg/m3 }\end{array}$ \\
\hline Sample 4. & $\begin{array}{l}\text { M/s. Pimpri } \\
\text { Chinchwad Municipal } \\
\text { Corporation, Pimpri) }\end{array}$ & $\begin{array}{l}12 \text { mm thick Polycarbonated } \\
\text { Noise Barrier Hexagonal/01- } \\
\text { Inner cells Hexagonal in } \\
\text { section }\end{array}$ & $\begin{array}{l}12 \text { mm thick Polycarbonated } \\
\text { Noise Barrier Rectangle/02- } \\
\text { Inner cells rectangular in } \\
\text { section }\end{array}$ \\
\hline Sample 5. & $\begin{array}{l}\text { M/s. Pimpri } \\
\text { Chinchwad Municipal }\end{array}$ \\
\hline
\end{tabular}

\section{Results and discussion}

The scope of this paper is the prediction of sound transmission loss (STL) of different panel systems as typically used by the building industry. Experimental and theoretical methods are used to estimate the acoustic performance of typical panels. The construction details of these panels are described in Table 1 . The sample 1 is $2 \mathrm{~mm}$ mild steel panel coated with $2 \mathrm{~mm}$ sound insulating polyurethane (PU) Shivabond 603 paint (total thickness $4 \mathrm{~mm}$ ), its measured STC value is 39 and predicted value is 38 . Sample 2 is same in thickness as sample 1 . However the 4 mm thick Aluminum Composite Panel with simple design paint have measured STC value is 26 and predicted value is 29. Both sample 1 and 2 have same thickness but sample one STC value is high as compared to the sample 2 STC value due to the acoustical polyurethane paint. PU paints are broadly known for their inherent toughness and flexibility. Shivabond 603 is a specially formulated two-component polyurethane paint; it is used for sound insulation purposes. 
Sample 3 is a high density (550-650 Kg/m3) $150 \mathrm{~mm}$ concrete block and its STC value is highest than sample one and two. Wes (2007) reported that solid concrete walls are great for sound insulation particularly when used in floors and walls due to the material's rigidity, i.e., it will not flex and create sound waves on the inaudible side of the wall. Nothing stops sound waves to a certain extent like massive materials. Concretes are mainly capable of stopping the critical low frequencies that are so tough to stop with less massive materials. Brick and Stone are very alike to concrete in mass. Steel is a quite dense material but not as concrete, and its density actually becomes an obligation in structural uses where its dense nature causes it to carry sound vibrations for long distances. Mass theory also has been used for the prediction of STC of sample 1 to 3 . The results from sound transmission loss measurements for the different materials are presented in figure 2 to 4 . It is observed from the figures that for the sample 1 and 3 the predicted transmission loss shows good agreement with the measured results while for sample 2 measured and predicted results match closely except for $3250 \mathrm{~Hz}$.

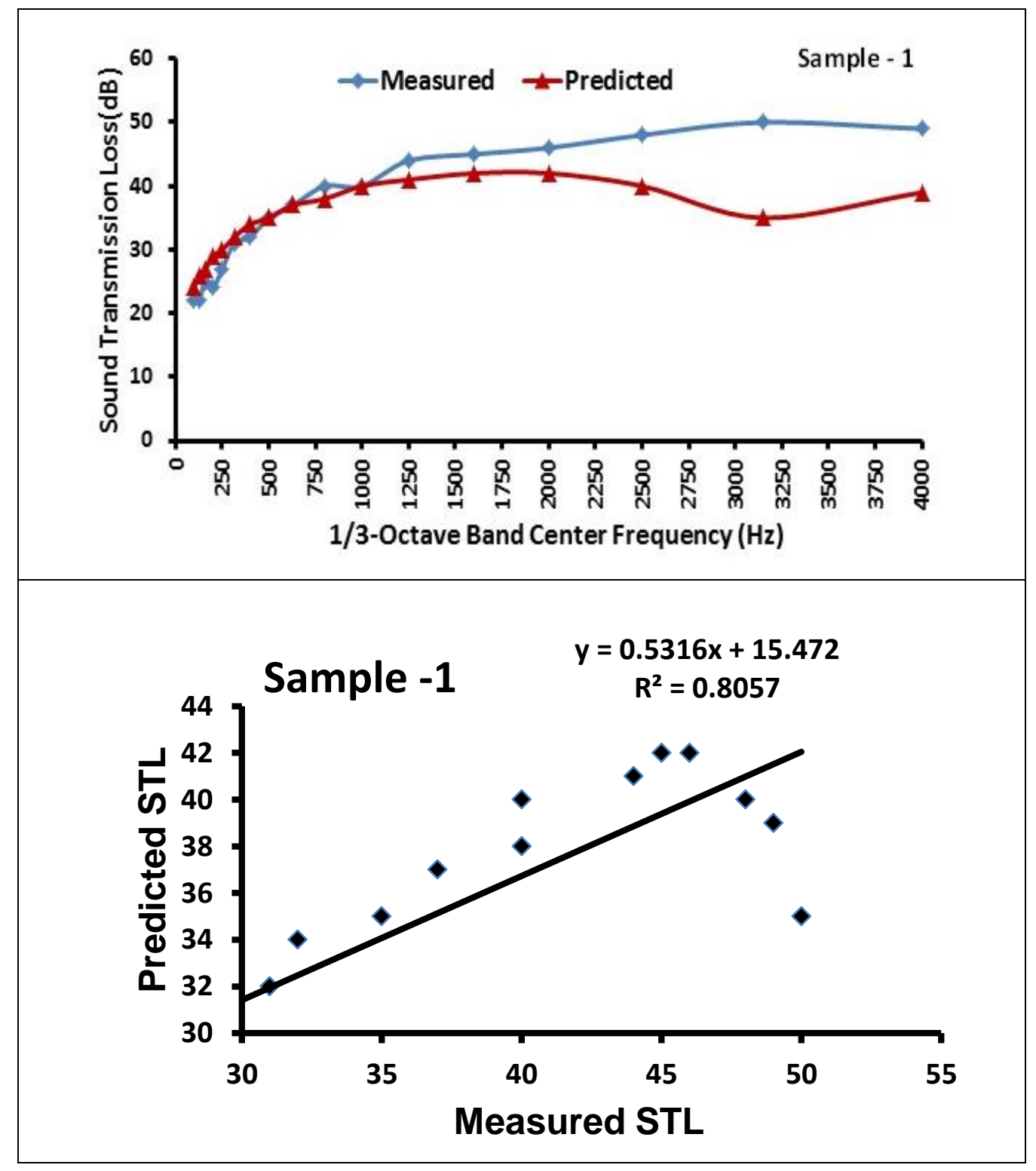

Fig. 2. Sound transmission loss as a function of frequency for sample 1.

Apart from the Steel, Aluminium and Concrete materials two layer Polycarbonated panel of $12 \mathrm{~mm}$ thickness (i.e., Sample 4 and 5) with hexagonal and rectangle structure inner cell 
structure have also been studied and shown in figure 5. The Polycarbonated panel with different inner cell structures is used as a noise barrier. Noise barriers are the best effective technique of mitigating roadway, industrial, and railway noise sources other than termination of the source activity. From figure 5 it is observed that the inner layer structure also influence the STC results. Higher sound transmission loss value has been observed for rectangle inner cell (i.e., STC 21) than the hexagonal inner cell (i.e., STC 19). Numbers of sound bridges are higher in hexagonal structure than the rectangle structure. Hence, the STC value is high for rectangle structure than the hexagonal structure.

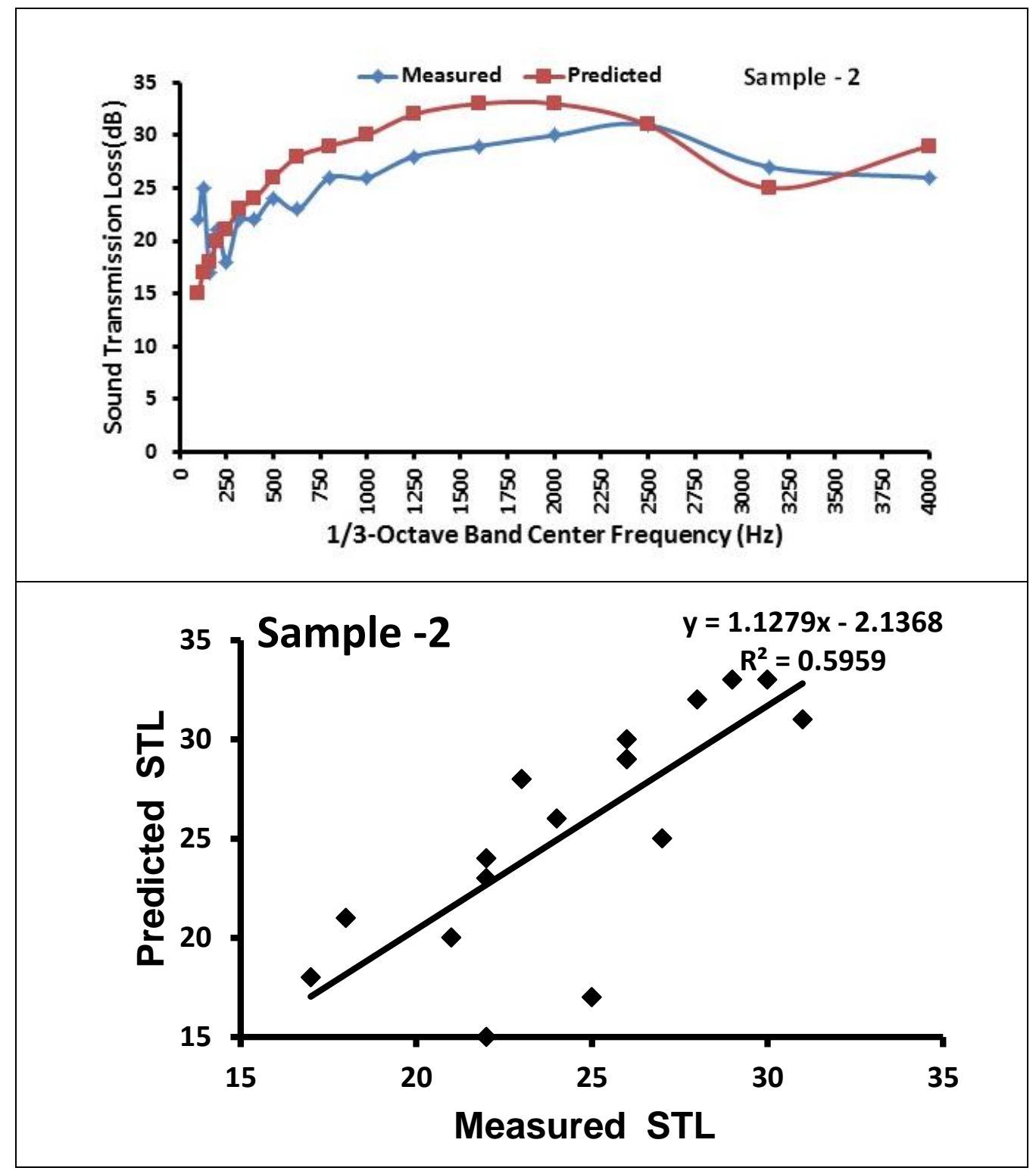

Fig. 3. Sound transmission loss as a function of frequency for sample 2. 


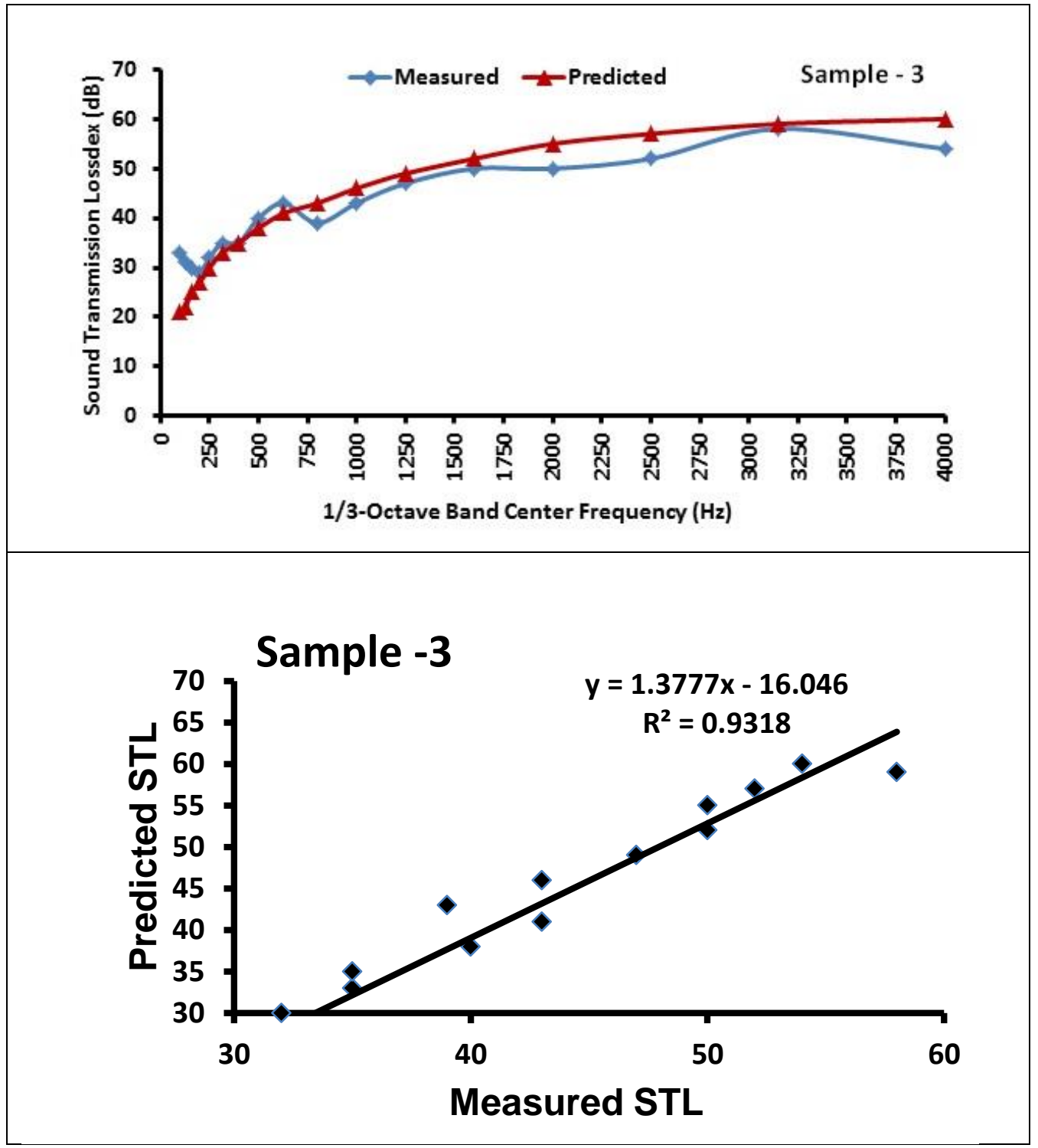

Fig. 4. Sound transmission loss as a function of frequency for sample 3.

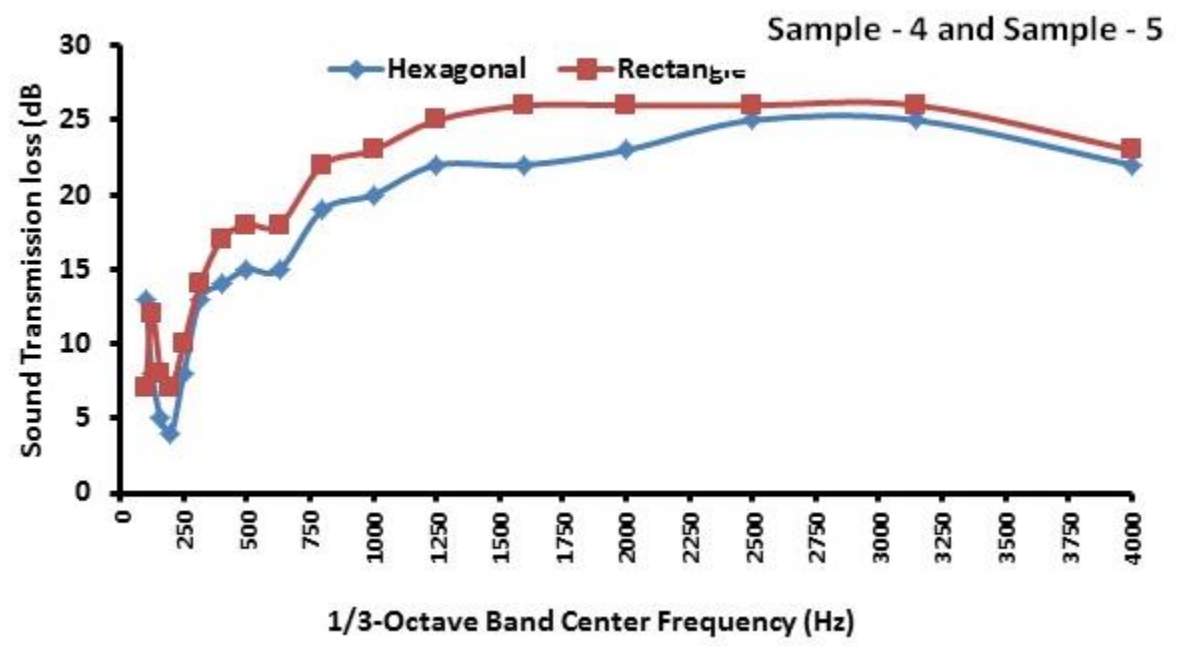

Fig. 5. Sound transmission loss as a function of frequency for sample $4 \& 5$. 


\section{Conclusions}

This paper examines the sound transmission loss (STL) through different panel materials commonly used in the building industry. Experimental and predictive methods are used to evaluate the acoustic performance of these materials and to improve their acoustic performance with noise treatment.

- Predicted results show better agreement with experimental results for different configuration of acoustics materials.

- Materials with high density and with acoustic paint represent high STC.

- Acoustic Coat is an inexpensive, easy to apply, sound deadening paint providing both sound deadening and insulation properties to painted ceilings and walls etc.

- From the rectangle and hexagonal inner cell structure study, it is observed that inner cell structure play an important role, for high STC value sound bridges in the inner cell structure should be minimum..

\section{References}

ASTM E413-87, Classification for Rating Sound Insulation (American Society for Testing and Materials, Washington DC,USA) 1999.

ISO 16283-1:2014 Acoustics -- Field measurement of sound insulation in buildings and of building elements -- Part 1: Airborne sound insulation

Jung, J.-D., Hong, S.-Y., Song, J.-H. and Kwon, H.-W. (2015) A Study on Transmission Loss Characteristics of Honeycomb Panel for Offshore Structures. Journal of Applied Mathematics and Physics, 3, 172176. http://dx.doi.org/10.4236/jamp.2015.32027

Lawrence E. Kinsler, Austin R. Frey, Alan B. Coppens and James V. Sanders (1982). Fundamentals of Acoustics, third Edition, John wiley \& sons.

Lin, H.-J., Wang, C.-N. and Kuo, Y.-M. (2007) Sound Transmission Loss across Specially Orthotropic Laminates. Applied Acoustics, 68, 1177-1191. http://dx.doi.org/10.1016/j.apacoust.2006.06.007

Moore, J.A. and Lyon, R.H. (1991) Sound Transmission Loss Characteristics of Sandwich Panel Constructions. J Acoust Soc Am, 89, 777-791.

Wang, S.C., Deng, Z.X. and Shen, W.D. (2010) Sound Transmission Loss Characteristics of Unbounded Orthotropic Sandwich Panels in Bending Vibration Considering Transverse Shear Deformation. Composite Structures, 92, 2885- 2889. http://dx.doi.org/10.1016/j.compstruct.2010.04.014

Wes L., (2007). Materials and Their Uses in Architectural Acoustics. Taliesin in Spring Green, Wisconsin, on July 19, 2007,http://www.weslachot.com/new/articles materials content.html. 